\title{
Repetition effect with picture stimuli: Possible implications for clarity
}

\author{
GUY L. ROWLAND and ROBERT E. FRANKEN \\ The University of Calgary, Calgary, Alberta, Canada
}

\begin{abstract}
Increasing recognition accuracy with repeated presentations was demonstrated for complex pictorial stimuli (real-world photographs) by accuracy, signal detection, and confidence of decision indicators. Consistent with other research, the effect occurred only for short stimulus durations. The effect occurred for both old and new pictures, the rate of improvement being greater for old than for new pictures. Experiment II utilized focus-degraded stimuli to demonstrate that amount of information artifacts were not responsible for the observed differences between responses to old and new pictures.
\end{abstract}

The recognition accuracy for tachistoscopically presented stimuli increases with repeated presentations (Haber, 1969; Haber \& Hershenson, 1965; Haber \& Standing, 1968; Haber, Standing \& Boss, 1970; Hershenson \& Haber, 1965; Weintraub \& McNulty, 1973). This effect, whose theoretical significance has been discussed by Dodwell (1971) and Doherty and Keeley (1972) has been investigated only with semantic stimuli (letters and words) and "nonsense" line stimuli. The present study was designed to investigate the effect with complex "real-world" photographs as stimuli. Both new (not previously viewed) and old (previously viewed) pictures were utilized.

\section{EXPERIMENT I}

\section{Method}

Four groups of unpaid volunteer university students were shown 150 rear-projected $35-\mathrm{mm}$ color slides (photographs of country, city, machinery, animals, etc.). The slides were projected on a $1 \times 1 \mathrm{~m}$ rear-projection screen by a Kodak Carousel Model 800 slide projector equipped with a $127-\mathrm{mm}$ lens, a Gerbrands Model G1165 shutter controlled by a Davis Model D-501 interval timer. Participants were seated $3.5 \mathrm{~m}$ from the screen. Each slide was presented for $5 \mathrm{sec}$ with a $1 \mathrm{sec}$ intertrial interval. Immediately after viewing the entire set of 150 slides, a recognition test was administered, consisting of 15 of the previously viewed slides, randomly selected and mixed with 15 new slides. These stimuli were utilized by Franken and Davis (1975), who demonstrated that task performance was not significantly altered by the use of either subset of 15 test pictures as old or new. The test stimulus exposure durations selected were $20,200,500$, and 1,000 msec. An auditory ready signal preceded each stimulus presentation by $1 \mathrm{sec}$. Groups of $10,9,9$, and 12 university student volunteers were assigned to each of the four durations, respectively. The 30 test stimuli were each presented for five successive trials, with a 5-sec intertrial interval. Following each trial, participants marked "yes" or "no" with respect to recognition, and indicated their level of confidence on a 5-point scale (ranging from "completely sure" to "guessing").

\section{Results and Discussion}

Both task performance and discriminability $\left(d^{\prime}\right)^{1}$ of
Table 1

Hit Rate, False Alarm Rate, $d^{\prime}$, and $\beta$ as a Function of Stimulus Duration

\begin{tabular}{lrrrr}
\hline & \multicolumn{4}{c}{ Duration (in msec) } \\
\cline { 2 - 5 } & 20 & 200 & 500 & 1000 \\
\hline Hit & .71 & .77 & .75 & .88 \\
False Alarm & .03 & .06 & .02 & .02 \\
d $^{\prime}$ & 2.23 & 2.36 & 2.67 & 3.13 \\
$\beta$ & 4.54 & 2.42 & 6.12 & 3.71 \\
\hline
\end{tabular}

stimuli improved with increasing exposure duration. These findings, presented in Table 1, are in agreement with previous work (Franken \& Rowland, 1974; Loftus, 1972). Task performance, stimulus discriminability, and confidence of decision changed significantly over trials only for the $20-\mathrm{msec}$ group. The task performance and signal detection data for this group are presented in Table 2. The increase in $\mathrm{d}^{\prime}[F(4,45)=6.95, p<.01]$ resulted from improvements in the hit rate. The consistently low false alarm rates observed for all conditions reflects that the participants adopted a conservative decision criterion.

Changes over trials in the confidence of decision ratings were demonstrated only at the $20-\mathrm{msec}$ duration. The Stimulus Type by Trial interaction $[F(4,72)=3.90$, $p<.01]$ reflects the fact that confidence (of correct decisions) increased more rapidly over trials for new than for old stimuli. A simple main effect analysis demonstrated that only the confidence for correct decisions to new stimuli increased $[F(4,45)=3.90, p<.01]$ An

Table 2

Hit Rate, False Alarm Rate, $d^{\prime}$, and $\beta$ as a Function of Trials for the 20-msec Group

\begin{tabular}{lccccc}
\hline & \multicolumn{5}{c}{ Trial } \\
\cline { 2 - 6 } & 1 & 2 & 3 & 4 & 5 \\
\hline Hits & .64 & .68 & .72 & .75 & .75 \\
False Alarms & .04 & .04 & .03 & .03 & .03 \\
$\mathrm{~d}^{\prime}$ & 1.74 & 2.02 & 2.67 & 2.36 & 2.36 \\
$\beta$ & 4.33 & 4.14 & 4.92 & 4.65 & 4.65 \\
\hline
\end{tabular}



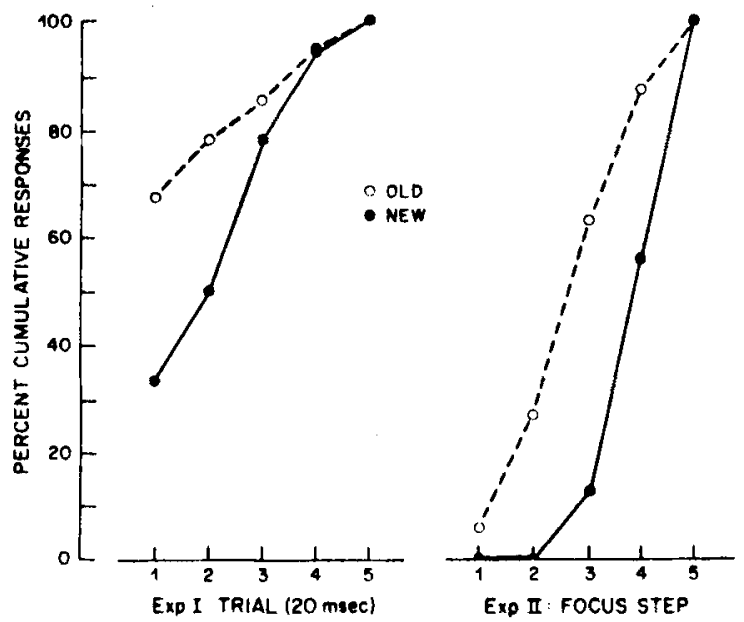

Figure 1. Trial or focus step on which maximum confidence of decision was first expressed for correct decisions. Cumulative percentages are shown only for the 20-msec group of Experiment I.

analysis of the trial on which maximum confidence of decision for correct responses was first expressed (Figure $1)$ indicated that full confidence occurred earlier for old $(M=1.74)$ than for new $(M=2.70)$ stimuli $[F(14,174)=$ $54.78, p<.01)$.

These data demonstrate that the effect is not limited to relatively simple or semantic stimuli but also occurs with complex "real-world" stimuli. As with simple stimuli, the effect with complex stimuli occurs only with brief presentations. The signal detection analysis suggests that the improving recognition accuracy resulted from increasing discriminability and not a changing decision criterion.

The data further indicate that recognition accuracy improves more rapidly for old than for new stimuli. This effect may be interpreted in several ways. First, the observed difference could be response bias produced; however, the increasing $\mathrm{d}^{\prime}$ and relatively stable values of $\beta$ do not lend weight to this interpretation. Second, that information stored in memory is accessed and interacts with the extant stimulus, enhancing the processing of the information from the old pictures. Finally, that more information is required to accurately identify an old picture than is required to detect a new picture. Experiment II was designed to test the latter interpretation.

\section{EXPERIMENT II}

Assuming the recognition-memory decision to involve a template-like, point-by-point matching process leads to the prediction that less information is required for the correct rejection of a new stimulus than for the confirmation of an old stimulus. A new stimulus could be accurately rejected if only one or a few points mismatched, while the accurate confirmation of an old stimulus would depend upon the matching of many or all points. Thus the recognition memory for degraded stimuli should be superior for new stimuli as information remaining in the degraded stimulus could provide the few mismatched points needed for a correct rejection. This prediction, of course, assumes a large number of points being matched and decision criteria of the magnitude reported in Experiment I.

\section{Method}

The stimulus material, both original presentation and test items, and the general method of Experiment I were utilized in this study. Each test stimulus was presented for $5 \mathrm{sec}$ for each of five successive trials, with the focus improving on each successive test trial. On Trial 1, the slide was out of focus (projector lens moved out as far as possible). The focus was improved for each of the following trials, with the stimulus being presented in focus on Trial 5. The focus was improved by moving the lens toward the focus position in increments of $5 / 16,4 / 16$, and $3 / 16$ of the distance of the Trial 1 lens position to the focus positions for Trials 2 through 5 , respectively. As a given optical operation does not equally degrade each of a series of complex photographs, particularly color cues, the convenient lens positioning operation was utilized. Seven university student volunteers participated in the study.

\section{Results and Discussion}

Both task performance and stimulus discriminability improved with improving focus. These findings are presented in Table 3. The increase in $\mathrm{d}^{\prime}$ over focus steps resulted from the concomitant improvement in both hit rate $[F(4,24)=31.20, p<.01]$ and false alarm rate $[F(4,24)=8.13, p<.01]$. Participants changed their decision criteria with improving focus. The mean decision criterion, $\beta$, for each participant was calculated and found to increase across focus steps $[F(4,24)=$ $20.55, p<.01]$. An analysis of the trial on which maximum confidence of decision was first expressed (Figure 1) indicated that full confidence occurred earlier for old stimuli $(M=3.43)$ than for new stimuli $(M=4.2)[F(1,894)=13.40, p<.01]$. The above data are in keeping with the comments of some subjects that some pictures seemed to "snap" into focus while still degraded, this occurring earlier (under greater focus degradation) for old than for new pictures.

Therefore the hypothesis that less information is required for the correct rejection of new pictures than for the detection of old pictures is not supported by these results.

Table 3

Hit Rate, False Alarm Rate, $d^{\prime}$, and $\beta$ as a Function of Focus Degradation

\begin{tabular}{lccccc}
\hline & \multicolumn{5}{c}{ Focus Degradation Step } \\
\cline { 2 - 6 } & 1 (Out) & \multicolumn{1}{c}{2} & \multicolumn{1}{c}{3} & 4 & 5 (In) \\
\hline Hits & .28 & .41 & .54 & .68 & .73 \\
False Alarms & .28 & .23 & .13 & .05 & .03 \\
$\mathrm{~d}^{\prime}$ & .00 & .53 & 1.23 & 2.08 & 2.55 \\
$\beta$ & 1.00 & 1.28 & 1.88 & 3.49 & 4.83 \\
\hline
\end{tabular}




\section{GENERAL DISCUSSION}

The results of Experiment I indicate that the repetition-accuracy effect also exists for complex pictures and that the recognition accuracy for old and new pictures increases at different rates. These differential rates do not seem to be response bias produced or produced by amount of information artifacts (Experiment 2). Rather, they would seem to be mediated by memory processes. The 5-sec intertrial interval utilized precludes explanation of the effect solely by iconic storage which terminates in several hundred milliseconds (Sperling, 1960). Thus these data provide evidence that information in memory can be accessed and utilized to enhance recognition decisions. The question still remains as to the "mechanism" by which the enhancement is accomplished.

Haber (1969) has proposed that the accuracy increases are mediated by increasing perceptual clarity, suggesting that the memory retrieval is of perceptual information. Dodwell (1971) has likened the process to an autocorrelator which stores information to be correlated with future information, providing an increasingly precise analysis of the information. Doherty and Keeley (1972) have suggested that the phenomena may be explained in terms of the decision processes involved. Unfortunately, the present study will not discriminate between these positions, and the nature of the mediational process remains obscure. Hopefully the techniques of the present studies may be utilized to study the learning/memory/perception interface.

\section{REFERENCES}

Dodwell, P. C. On perceptual clarity. Psychological Review, $1971,78,275-288$.

DOHERTY, M. E., \& KeELEY, K. M. On the identification of repeatedly presented brief visual stimuli. Psychological Bulletin, 1972, 78, 142-154.
Franken, R. E. \& Davis. J. Predicting memory for pictures from rankings of interestingness, pleasingness, complexity, figure-ground and clarity. Perceptual and Motor Skills, $1975,41,243-247$.

Franken, R. E., \& Rowland, G. L. Visual memory: Accuracy of decisions of familiar-novel for tachistoscopically presented stimuli. Perceptual and Motor Skills, 1974, 38, 1039-1043.

HABER, R. N. Repetition as a determinant of perceptual recognition processes. In $R$. N. Haber (Ed.), Information processing approaches to visual perception. New York: Holt, Rinehart and Winston. 1969.

Haber, R. N., \& Hershenson, M, Effects of repeated brief exposures on the growth of a precept. Journal of Experimental Psychology, 1965, 69, 40-64.

HABER, R. N.. \& Standing, L. G. Clarity and recognition of masked and degraded stimuli. Psychonomic Science. 1968. 13, 83-84.

Haber, R. N., Standing, L. G., \& Boss, J. Effect of position and typeface variation on perceptual clarity. Psychonomic Science, 1970. 18. 91-92.

Hershenson, M.. \& Haber, R. N. The role of meaning in the perception of briefly exposed words. Canadian Journal of Psychology, 1965, 19, 42-46.

LofTus. G. R. Eye fixations and recognition memory for pictures. Cognitive Psychology, 1972, 3. 252-551.

SPERLing, G. The information available in brief visual presentations. Psychological Monographs, 1960, 74(No. 489).

Weintraue, D. J., \& McNulty, J. A. Clarity versus identifiability of repeatedly flashed patterns. Journal of Experimental Psychology, 1973, 99, 293-305.

\section{NOTE}

1. The values of $d^{\prime}$ and $\beta$ reported in the table are averages of individual within-trial performances. The small number of responses coupled with rounding errors invalidate any strict interpretation of these indices.

(Received for publication May 3. 1975; revision received April 19, 1976.) 